\title{
Predictors of hormonal and metabolic disorders of arterial hypertension and type 2 diabetes mellitus comorbidity
}

\author{
Oleksandr Bilovol \\ Department of Clinical Pharmacology, Kharkiv National Medical University, 61000 Kharkiv, Ukraine.
}

Correspondence to: Prof. Oleksandr Bilovol, Department of Clinical Pharmacology, Kharkiv National Medical University, 2A Malaya Avenue, 61000 Kharkiv, Ukraine. E-mail: Bilovol.Oleksandr@rada.gov.ua

How to cite this article: Bilovol O. Predictors of hormonal and metabolic disorders of arterial hypertension and type 2 diabetes mellitus comorbidity. Vessel Plus 2017;1:22-8.

\begin{tabular}{l} 
Article history: \\
Received: 26-10-2016 \\
Accepted: 02-03-2017 \\
Published: 31-03-2017 \\
\hline Key words: \\
Hypertension, \\
type 2 diabetes mellitus, \\
adipokines, \\
interleukins
\end{tabular}

\begin{abstract}
Aim: These experiments studied adipokine and interleukin imbalances during the development and progression of metabolic disorders in patients with arterial hypertension (AH) and type 2 diabetes mellitus (T2DM). Methods: Ninety-five patients with stage II second degree AH (53 males and 42 females, mean age $54.7 \pm 5.4$ years) were observed. The cohort was separated into: group $1(n=48)$ patients with AH and group $2(n=47)$ patients with both $\mathrm{AH}$ and T2DM. Serum protein levels of omentin, adiponectin, tumor necrosis factor-alpha (TNF- $\alpha$ ), C-reactive protein (CRP), resistin, interleukin (IL)-1 $\beta$, IL-4, and IL-6 were measured. Lipid and carbohydrate metabolism rates were assessed. Results: Peak homeostatic model assessment for insulin resistance (HOMA-IR) index values, as well as circulating insulin and CRP levels, were observed in group 2. Reduced adiponectin levels negatively correlated with HOMA-IR indices $(r=-0.52, P<0.05)$, triglycerides $(r=-0.52$, $P<0.05)$, glucose levels $(r=-0.44, P<0.05)$, body mass indices $(r=-0.44, P<0.05)$, and HbAlc levels $(r=-0.57, P<0.01)$. Group 2 patients demonstrated low omentin levels and high resistin and TNF- $\alpha$ levels. Negative correlations between IL- 6 and both omentin and adiponectin $(r=-0.46, P<0.01 ; r=-0.42, P<0.01$, respectively) were observed. Conclusion: A novel pathogenic link was demonstrated between metabolic disorders, adipokines, and pro-inflammatory IL-6 levels as negative regulators of comorbid AH and T2DM.
\end{abstract}

\section{INTRODUCTION}

Arterial hypertension $(\mathrm{AH})$ is an important public health challenge in both economically developing and developed countries. ${ }^{[1]}$ The reported prevalence of $\mathrm{AH}$ has varied globally; the lowest prevalences was found in rural India (3.4\% in men and $6.8 \%$ in women) and the highest was observed in Poland $68.9 \%$ in men and
$72.5 \%$ in women). ${ }^{[2]}$ Sur et al. ${ }^{[3]}$ in 2010 reported that more than 3 million people in Romania are hypertensive. In 2009, one-fifth of the adult Danish population was hypertensive. ${ }^{[4]}$ Hypertension affects nearly 75 million adults in the USA and is a major risk factor for myocardial infarction, ischemic stroke, chronic kidney disease, and vascular disease. According to an analysis of American data from the Nationwide Emergency Department

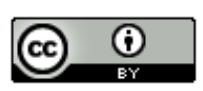

This is an open access article licensed under the terms of Creative Commons Attribution 4.0 International License (https://creativecommons.org/licenses/by/4.0/), which permits unrestricted use, distribution, and reproduction in any medium, as long as the original author is credited and the new creations are licensed under the identical terms.

For reprints contact: service@oaepublish.com

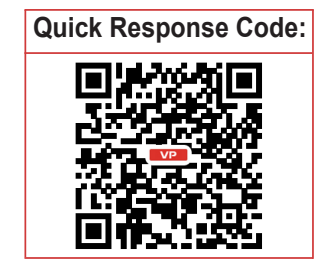


Sample, there was a $25 \%$ increase in the number of people visiting emergency rooms for hypertensionrelated procedures between 2006 and 2011. ${ }^{[5]} \mathrm{A}$ 25-year epidemiological study has been devoted to situational dynamics related to $\mathrm{AH}$ in the Ukraine. The report enrolled urban residents aged 18-64 years and indicated that $\mathrm{AH}$ prevalence grew from $30.6 \%$ to $35.3 \%(P>0.05)$ over the observation period, probably due to increased average systolic arterial pressure levels. ${ }^{[6]}$ The study also revealed a preponderance of risk factors among patients with $\mathrm{AH}$. Only $5.6 \%$ of $\mathrm{AH}$ patients exhibited zero risk factors. Strikingly, $25.4 \%$ of $\mathrm{AH}$ patients had one risk factor, $33.2 \%$ of patients had 2 risk factors, and 3 or more risk factors were reported in $35.8 \%$ of patients. Unfortunately, the epidemiologic environment contributing to $\mathrm{AH}$ remains unfavorable. The Ukrainian data suggest that the $\mathrm{AH}$ high-risk profile is common. ${ }^{[6]}$ Thus, it is unlikely that a noticeable decline in the death rate of this population will occur in the near future. A significant number of individuals with $\mathrm{AH}$ are unaware of their disease. Among those with diagnosed hypertension, treatments are frequently inadequate and incidence of deaths due to hypertension complications is high.

Isolated AH is currently rare. More commonly, physicians encounter clinical situations in which cases of $\mathrm{AH}$ are associated with endocrinopathies. The turn of the 21st century was marked by significant prevalence of type 2 diabetes mellitus (T2DM). Increases in incidence worldwide led to discussions about the global diabetes epidemic. The World Health Organization reported in 2016 that the number of people with diabetes mellitus rose from 108 million in 1980 to 422 million in 2014. Among adults over 18 years of age, diabetes mellitus rates rose from $4.7 \%$ in 1980 to $8.5 \%$ in $2014 .{ }^{[7]}$ Given that diabetes mellitus disables patients at very early ages and leads to high mortality rates, the fight against diabetes has been elevated to a top priority for national health care systems across the world.

According to epidemiological studies, in patients with a combination of hypertension and T2DM the risk of fatal coronary heart disease increases 3 to 5 times, stroke increases 3 to 4 times, complete loss of vision increases 10 to 20 times, uremia increases 20 to 25 times, and gangrene of lower extremities becomes 20 times more likely. ${ }^{[8]}$

One explanation for the frequent observation of comorbid type 2 diabetes in hypertensive patients is that the prevalence of overweight and obesity in the population has increased. ${ }^{\left[{ }^{[9}\right.}$ Prospective studies have shown a strong relationship between obesity and type 2 diabetes. Almost $90 \%$ of patients with T2DM are obese. Similarly, the risk of hypertension is $50 \%$ higher in obese patients compared to those in normal weight ranges.

In the last few years, inflammatory mechanisms have been shown to regulate initiation, maintenance, and development of cardiovascular disease. Associations between cardiovascular diseases and obesity are mediated, in part, by secretory regulation of adipose tissue. Adipose tissue secretes bioactive peptides (adipokines), which have local and distal influences on organ systems through autocrine, paracrine, and endocrine functions. Increased production of adipokines in obese patients impacts multiple bodily functions, many of which are linked with cardiovascular diseases, such as: insulin sensitivity, immunity, angiogenesis, hemostasis, lipid metabolism, and blood pressure. Adipocytes, like T-lymphocytes and macrophages, produce cytokines and are involved in complement activation-stimulating inflammatory signaling cascades. ${ }^{[3,8]}$ Cytokine imbalance is a wellestablished mechanism contributing increased risk of vascular complications. Therefore, elucidating the interaction between adipokines, interleukins, and metabolic disorders in patients with $\mathrm{AH}$ and T2DM is relevant.

The present study was undertaken to investigate the effects of adipokine and interleukin imbalances on the development and progression of metabolic disorders in patients managing hypertension with comorbid type 2 diabetes.

\section{METHODS}

\section{Patients}

Ninety-five patients with stage II second degree arterial hypertension (53 males and 42 females) were assessed. The mean age of the cohort was $54.7 \pm 5.4$ years. The patients were sub-divided into 2 groups. Group $1(n=48)$ consisted of hypertensive patients without T2DM. Group $2(n=47)$ was a comorbid population with both $\mathrm{AH}$ and T2DM. The control group consisted of 20 age- and gender-matched healthy subjects. AH diagnoses were conducted according to guidelines for the management of arterial hypertension from the European Society of Cardiology (ESC) and the European Society of Hypertension (2013), as well as Ukrainian Cardiology Association recommendations (2013). ${ }^{[10]}$

Criteria supporting diagnosis of abdominal obesity were established based on recommendations by the World Health Organization (1997). Anthropometric measurements were used to calculate body mass 
index (BMI). The severity of obesity was determined following guidance from the International Diabetes Federation (2015). Diagnoses of type 2 diabetes were made following general recommendations of the European Association for the Study of Diabetes (2013) and the ESC (2013). ${ }^{[11]}$ Inclusion criteria: fasting blood glucose $\leq 8.5 \mathrm{mmol} / \mathrm{L}$, postprandial hyperglycemia $\leq$ $11 \mathrm{mmol} / \mathrm{L}$, and $\mathrm{HbA} 1 \mathrm{c}$ level $\leq 9 \%$. Exclusion criteria: pregnancy or lactation; self-reporting with insulindependent diabetes, previous acute myocardial infarction or ischemic stroke; cardiovascular damage $\geq$ II by New York Heart Association criteria; liver disease indicated by transaminase values more than 3 times greater than normal; chronic kidney disease with serum creatinine > $2 \mathrm{mg} / \mathrm{dL}$; ongoing dialysis; human immunodeficiency virus positive disease; history of chronic alcohol abuse in the last 2 years; or history of cancer, stroke, or organ transplantation.

\section{Enzyme-Linked ImmunoSorbent Assay}

Serum concentrations of omentin (BioVendor, Czech Republic), adiponectin, tumor necrosis factor-alpha (TNF- $\alpha$ ), C-reactive protein (CRP) - DRG Elisa, USA and resistin (MBL International Corporation, USA) were determined with ELISA. Serum concentrations of interleukin (IL)-1, IL-4, and IL-6 were also determined by Enzyme-Linked ImmunoSorbent Assay (ELISA, Protein Contour, St. Petersburg). All assays were tested per the manufacturers' guidelines.

\section{Lipid metabolism assays}

Total cholesterol (TC) in plasma, high-density lipoprotein (HDL), and triglyceride (TG) levels were determined in all patients by enzymatic methodologies on a Humalyser autoanalyzer (Human Company, Germany). Low-density lipoprotein (LDL) cholesterol content was calculated using the Friedewald W. T. formula: LDL cholesterol $(\mathrm{mmol} / \mathrm{L})=\mathrm{TC}-\mathrm{HDL}$ cholesterol - TG/2.22. Whole blood HbA1c levels were determined by Reagent Test-Systems (Ukraine). Fasting plasma glucose levels was determined using glucose oxidase methodology. Fasting serum insulin levels were determined by ELISA. Glucose tolerance was measured using oral glucose tolerance tests. Homeostatic model assessment for insulin resistance (HOMA-IR) levels were calculated based on laboratory insulin and fasting glucose levels. HOMA-IR = fasting insulin $\times$ fasting glucose $(\mathrm{mmol} / \mathrm{L}) / 22.5$. HOMA-IR levels $>2.77$ were diagnosed as insulin resisted.

\section{Statistical analysis}

Statistical data analyses were performed using the general-purpose data processing software package in Statistica 8.0. Analyses of statistical significance were performed using Student's $t$-tests and non-parametric statistical methods.

\section{RESULTS}

Analyses of trophologic parameters revealed specific patterns in both groups. Patients with isolated $\mathrm{AH}$ (group 1) exhibited BMl measurements ranging from 18.5 to $24.9 \mathrm{~kg} / \mathrm{m}^{2}$ (4 patients). The majority of patients with isolated $\mathrm{AH}$ and comorbid $\mathrm{AH}$ with T2DM (group 2; $65.1 \%$ and $54.6 \%$, respectively) had BMI measurements ranging from 30 to $34.9 \mathrm{~kg} / \mathrm{m}^{2}$. Thirddegree obesity $\left(\mathrm{BMI}>40.0 \mathrm{~kg} / \mathrm{m}^{2}\right.$ ) was observed in 2 patients with isolated hypertension and in 6 patients with comorbid $\mathrm{AH}$ and T2DM.

Serum lipid spectra were altered with significantly higher frequency in patients with concomitant $\mathrm{AH}$ and T2DM rather than $\mathrm{AH}$ alone $(62.6 \%$ and $44.2 \%$, respectively; $P<0.05)$. Serum TG levels [Table 1] were 1.4 fold $(P=$ 0.0002 ) higher in group 2 patients (AH plus T2DM) than in group 1 patients (AH alone), and 1.5 fold higher than in the controls $(P=0.0020)$. HDL-C levels in group 2 patients were significantly reduced compared to controls (53.2\% and $21.0 \%$, respectively; $P=0.0020$ ). Group 2 patients with BMI measurements of 30 to $34.9 \mathrm{~kg} / \mathrm{m}^{2}$ had significantly lower levels of HDL-C compared with control patients $(P<0.05)$. Progression of lipid disorders in patients with comorbid $\mathrm{AH}$ and T2DM directly depended on BMI. Maximum TC and TG levels were observed in patients with BMI measurements of 35 to $40 \mathrm{~kg} / \mathrm{m}^{2}(P=0.242, P=0.062$, respectively), while HDL cholesterol serum concentrations were the lowest in these patients $(P=0.042)$.

Next, insulin resistance (IR) indices were analyzed in the cohort. Patients in group 2 exhibited significantly higher HOMA-IR index values, as well as insulin and C-peptide measurements, when compared to group 1 and the controls $(P<0.0001, P=0.0003, P=0.0004$, respectively) [Table 2]. These data indicated that hyperinsulinemic IR progression was associated with T2DM incidence. HOMA-IR indices in patients with $\mathrm{AH}$ alone were 2-fold higher than in controls $(P=0.00001)$. In patients with both $\mathrm{AH}$ and T2DM, HOMA-IR indices were 2.2-fold higher than in controls $(P=0.00001)$.

Regression analyses of these data identified statistically significant relationships between HOMA-IR levels and: glucose levels $(r=0.42, P=0.06)$, C-peptide levels $(r$ $=0.64, P=0.0001)$, BMI $(r=0.54, P=0.0054)$ and cholesterol levels $(r=0.64, P=0.056)$. These results supported the hypothesis that the development and progression of IR correlated with hyperinsulinemia and dyslipidemia. These data also suggest that IR was associated with inflammation and the development of 
Table 1: Characteristic of patient's lipid metabolism (mean \pm SD)

\begin{tabular}{|c|c|c|c|c|}
\hline Index & 1. Control group $(n=20)$ & 2. $\mathrm{AH}(n=48)$ & 3. $\mathrm{AH}+\mathrm{T} 2 \mathrm{DM}(n=47)$ & $P$ value \\
\hline Total cholesterol, $\mathrm{mmol} / \mathrm{L}$ & $4.90 \pm 0.64$ & $5.80 \pm 1.30$ & $6.10 \pm 1.70$ & $\begin{array}{l}P_{1-2}=0.0470 \\
P_{1-3}=0.0320 \\
P_{2-3}=0.7200\end{array}$ \\
\hline Cholesterol of high-density lipoprotein, $\mathrm{mmol} / \mathrm{L}$ & $1.20 \pm 0.06$ & $1.00 \pm 0.05$ & $0.700 \pm 0.045$ & $\begin{array}{l}P_{1-2}=0.5400 \\
P_{1-3}=0.0020 \\
P_{2-3}=0.0070\end{array}$ \\
\hline Triglycerides, $\mathrm{mmol} / \mathrm{L}$ & $1.80 \pm 0.07$ & $1.90 \pm 0.09$ & $2.70 \pm 0.16$ & $\begin{array}{l}P_{1-2}=0.7300 \\
P_{1-3}=0.0020 \\
P_{2-3}=0.0002\end{array}$ \\
\hline Cholesterol of low-density lipoprotein, $\mathrm{mmol} / \mathrm{L}$ & $3.20 \pm 0.54$ & $3.68 \pm 0.60$ & $4.04 \pm 0.97$ & $\begin{array}{l}P_{1-2}=0.2300 \\
P_{1-3}=0.0330 \\
P_{2-3}=0.0530\end{array}$ \\
\hline
\end{tabular}

AH: arterial hypertension; T2DM: type 2 diabetes mellitus

Table 2: Characteristic of insulin resistance indexes in observed patients (mean \pm SD)

\begin{tabular}{|c|c|c|c|c|}
\hline Index & 1. Control group $(n=20)$ & 2. $\mathrm{AH}(n=48)$ & 3. AH + T2DM $(n=47)$ & $P$ value \\
\hline HOMA-IR & $1.64 \pm 0.56$ & $4.47 \pm 0.60$ & $5.44 \pm 0.72$ & $\begin{array}{l}P_{1-2}=0.00001 \\
P_{1-3}=0.00001 \\
P_{2-3}=0.1500\end{array}$ \\
\hline Insulin, $\mu \mathrm{U} / \mathrm{mL}$ & $5.58 \pm 1.30$ & $11.10 \pm 2.70$ & $13.70 \pm 2.60$ & $\begin{array}{l}P_{1-2}=0.0003 \\
P_{1-3}=0.0002 \\
P_{2-3}=0.0470\end{array}$ \\
\hline C-reactive protein, $\mathrm{ng} / \mathrm{mL}$ & $0.490 \pm 0.025$ & $0.960 \pm 0.053$ & $1.300 \pm 0.075$ & $\begin{array}{l}P_{1-2}=0.0004 \\
P_{1-3}=0.0001 \\
P_{2-3}=0.0620\end{array}$ \\
\hline
\end{tabular}

HOMA-IR: homeostatic model assessment for insulin resistance; AH: arterial hypertension; T2DM: type 2 diabetes mellitus

vascular wall atherosclerotic lesions in patients facing both $\mathrm{AH}$ and T2DM. ${ }^{[12,13]}$

Next, glucose tolerance was tested. Impaired glucose tolerance (IGT) was observed in $9.6 \%$ of patients with hypertension only. In contrast, $96.5 \%$ of patients with both $\mathrm{AH}$ and T2DM were glucose intolerant. Also, $\mathrm{HbA} 1 \mathrm{c}$ was significantly increased in group 2 patients compared to controls $(P<0.05)$. These data affirmed that excess body weight had negative impacts carbohydrate metabolism [Table 3]. Furthermore, fasting serum glucose (FG) levels were significantly elevated in group 1 patients $(6.2 \%)$ compared to controls $(P=$ $0.034)$. This may result from abdominal obesity given that: (1) excess body weight is causally associated with IR development; and (2) we observed the highest FG levels in patients with both $\mathrm{AH}$ and T2DM.

Serum adiponectin levels were evaluated. Adiponectin levels were reduced in patients with both isolated $\mathrm{AH}$ and comorbid AH/T2DM when compared to controls [Table 4]. Hypoadiponectinemia was most apparent in group 2 patients $(P<0.05)$. Adiponectin levels negatively correlated with HOMA-IR indices $(r=-0.52, P<0.05)$, TG levels $(r=-0.52, P<0.05)$, glucose levels $(r=-0.44$, $P<0.05)$, BMI $(r=-0.44, P<0.05)$ and HbA1c $(r=$ $-0.57, P<0.01)$. These data supported that adiponectin regulated carbohydrate and lipid metabolisms and was deregulated in cases of IR. Currently, IR is considered a major risk factor contributing to etiology of T2DM, hypertension, dyslipidemia, atherosclerotic vascular disease, and, potentially, coronary heart disease and stroke. ${ }^{\left[{ }^{13-15]} I R\right.}$ can also predict development of T2DM in individuals who are normoglycemic. Therefore, it is important to identify IR in the pre-diabetic or early disease stages when therapeutic interventions are most likely to succeed.

Further analyses identified a correlation between adiponectin levels and BMI. In patients with $\mathrm{AH}$ and T2DM, those with a BMl ranging from 25.0 to $29.9 \mathrm{~kg} / \mathrm{m}^{2}$ had an average adiponectin level of $12.2 \pm 3.6 \mathrm{ng} / \mathrm{mL}$. When group 2 patients had BMls ranging from 35.0 to $39.5 \mathrm{~kg} / \mathrm{m}^{2}$, average adiponectin level dropped to $7.4 \pm 2.2 \mathrm{ng} / \mathrm{mL}(P<0.05)$. These results suggest that adiponectin levels could be used to identify the development of vascular atherosclerotic lesions in patients with comorbid AH and T2DM [Table 4].

Next, omentin serum levels were evaluated. Patients with both $\mathrm{AH}$ and T2DM had 1.5-fold lower serum omentin than control patients $(P=0.044)$, as well as significantly lower omentin than $\mathrm{AH}$ patients $(P=$ 0.052). There were negative correlative relationships between omentin levels and: systolic blood pressure levels $(r=-0.61, P<0.05)$, diastolic blood pressure levels $(r=-0.68, P<0.001)$, BMI $(r=-0.36, P<0.05)$, TG levels $(r=-0.44, P<0.001)$, CRP $(r=-0.38, P$ $<0.001)$, and TNF- $\alpha(r=-0.44, P<0.001)$. Also, omentin levels positively correlated with HDL-C $(r=$ 
Table 3: Characteristic of carbohydrate metabolism indexes in observed patients (mean \pm SD)

\begin{tabular}{|c|c|c|c|c|}
\hline Index & 1. Control group $(n=20)$ & 2. $\mathrm{AH}(n=48)$ & 3. AH + T2DM $(n=47)$ & $P$ value \\
\hline Fasing glucose, $\mathrm{mmol} / \mathrm{L}$ & $4.27 \pm 0.94$ & $6.02 \pm 1.05$ & $7.76 \pm 1.92$ & $\begin{array}{l}P_{1-2}=0.0340 \\
P_{1-3}=0.0003 \\
P_{2-3}=0.0740\end{array}$ \\
\hline $\mathrm{HbA1c}(\%)$ & $4.50 \pm 0.85$ & $6.30 \pm 1.23$ & $8.70 \pm 1.52$ & $\begin{array}{l}P_{1-2}=0.0966 \\
P_{1-3}=0.0002 \\
P_{2-3}=0.0054\end{array}$ \\
\hline Oral glucose tolerance test, $\mathrm{mmol} / \mathrm{L}$ & $5.16 \pm 1.06$ & $10.42 \pm 1.89$ & $13.90 \pm 2.26$ & $\begin{array}{l}P_{1-2}=0.0001 \\
P_{1-3}=0.0000 \\
P_{2-3}=0.0100\end{array}$ \\
\hline
\end{tabular}

$\mathrm{AH}$ : arterial hypertension; T2DM: type 2 diabetes mellitus

Table 4: Levels of adipose tissue hormones and inflammatory markers in the studied patients (mean \pm SD)

\begin{tabular}{|c|c|c|c|c|}
\hline Index & 1. Control group $(n=20)$ & 2. $\mathrm{AH}(n=48)$ & 3. AH + T2DM $(n=47)$ & $P$ value \\
\hline Omentin, $\mathrm{ng} / \mathrm{mL}$ & $397.60 \pm 5.30$ & $319.52 \pm 11.92$ & $264.52 \pm 3.76$ & $\begin{array}{l}P_{1-2}=0.063 \\
P_{1-3}=0.044 \\
P_{2-3}=0.052\end{array}$ \\
\hline Adiponectin, $\mathrm{ng} / \mathrm{mL}$ & $13.60 \pm 2.10$ & $11.40 \pm 2.70$ & $7.30 \pm 1.83$ & $\begin{array}{l}P_{1-2}=0.097 \\
P_{1-3}=0.0002 \\
P_{2-3}=0.0056\end{array}$ \\
\hline Resistin, $\mathrm{ng} / \mathrm{mL}$ & $10.20 \pm 2.58$ & $10.30 \pm 2.80$ & $23.40 \pm 3.80$ & $\begin{array}{l}P_{1-2}=0.0971 \\
P_{1-3}=0.043 \\
P_{2-3}=0.049\end{array}$ \\
\hline TNF- $\alpha, p g / m L$ & $5.24 \pm 1.03$ & $12.24 \pm 1.60$ & $27.36 \pm 1.74$ & $\begin{array}{l}P_{1-2}=0.008 \\
P_{1-3}=0.0001 \\
P_{2-3}=0.0038\end{array}$ \\
\hline $\mathrm{IL}-1 \beta, \mathrm{pg} / \mathrm{mL}$ & $36.8 \pm 5.6$ & $86.2 \pm 6.3$ & $93.1 \pm 9.5$ & $\begin{array}{l}P_{1-2}=0.008 \\
P_{1-3}=0.001 \\
P_{2-3}=0.064\end{array}$ \\
\hline IL-6, pg/mL & $19.1 \pm 1.2$ & $33.5 \pm 3.7$ & $36.4 \pm 4.3$ & $\begin{array}{l}P_{1-2}=0.006 \\
P_{1-3}=0.002 \\
P_{2-3}=0.072\end{array}$ \\
\hline $\mathrm{IL}-4, \mathrm{pg} / \mathrm{mL}$ & $42.9 \pm 2.4$ & $69.1 \pm 3.4$ & $79.4 \pm 2.1$ & $\begin{array}{l}P_{1-2}=0.0031 \\
P_{1-3}=0.002 \\
P_{2-3}=0.041\end{array}$ \\
\hline
\end{tabular}

AH: arterial hypertension; T2DM: type 2 diabetes mellitus; TNF- $\alpha$ : tumor necrosing factor-alfa; IL: interleukin

0.46, $P<0.001)$ and adiponectin $(r=0.44, P<0.05)$. Additionally, negative correlations were observed between omentin and glucose levels $(r=-0.34, P$ $<0.05)$, as well as HOMA-IR indices $(r=-0.46, P<$ $0.001)$. These data suggested that omentin levels were involved in progression of metabolic disorders as well as atherosclerosis development in patients with comorbid hypertension and T2DM. Data gathered here support the hypothesis that abnormal omentin production may contribute to the pathogenesis of obesity-related complications, including T2DM and cardiovascular diseases such as $\mathrm{AH} .{ }^{[16-18]}$

The resistin cytokine is attracting considerable research interest, given that it may link obesity and diabetes. Resistin regulates inflammatory cascade activities, endothelial cell activations and proliferation of vascular smooth muscle cells. The cytokine is of interest as a potential link between metabolic and cardiovascular diseases. Resistin plasma levels were measured here.

Results revealed expression dynamics similar to those observed with insulin and glucose levels. Thus, patients with $\mathrm{AH}$ and T2DM experienced significantly higher resistin levels than patients with $\mathrm{AH}$ alone or than control patients $(P=0.049, P=0.043$, respectively). However, resistin levels between $\mathrm{AH}$ patients and controls were not significantly different $(P>0.05)$. In AH/T2DM comorbid patients, circulating blood resistin increased significantly, which correlated with fasting insulin, fasting glucose and lipid (TC and TG) concentrations. These data suggested that increased adiposity contributed to the etiology of changes in resistin levels. Previous data have provided ambiguous results when characterizing the role of resistin secretion in the pathogenesis of insulin resistance and T2DM. ${ }^{[18-20]}$ The presence of high serum resistin in these comorbid $\mathrm{AH}$ and T2DM patients suggested that it was an additional regulator of IR.

Next, the groups were tested for TNF- $\alpha$ serum levels. Both group 1 and group 2 patients experienced significant increases in serum TNF- $\alpha$ levels when compared with controls $(P<0.05)$. At their highest, TNF- $\alpha$ levels were 4.1-fold increased in AH/T2DM patients $(P=0.0001)$ [Table 4]. Increased TNF- $\alpha$ levels 
correlated with increased concentrations of TG and glucose $(r=0.415, P=0.001 ; r=0,042, P=0.014$, respectively).

Finally, both $\mathrm{AH}$ and $\mathrm{AH} / \mathrm{T} 2 \mathrm{DM}$ patients experienced significant increases in IL-1 $\beta$ levels when compared to controls. The most pronounced differences were observed in patients with both $\mathrm{AH}$ and T2DM $(P=$ 0.008 ). These results have been associated with presumptive stimulation of acute-phase protein syntheses occurring as a result of $\mathrm{AH}$ and T2DM. Additionally, IL-4 activities were increased and positive correlations were observed between IL-4 and IL-1 $\beta(r$ $=0.42, P<0.01)$ and IL-6 $(r=0.44, P<0.01)$. These data suggested that compensatory signaling activities were occurring, given that IL-4 has been regulated to promote stabilization of inflammation. The regularity in which comorbid $\mathrm{AH}$ and T2DM experienced alterations in metabolic signaling factors emphasized the systematic and patterned etiologies of metabolic disorders. Negative correlations between IL- 6 and both omentin and adiponectin $(r=-0.46, P<0.01 ; r=-0.42$, $P<0.01$, respectively) were observed. These findings were consistent with previous studies indicating that IL-6 regulated adipokine production. ${ }^{[18,21,22]}$

\section{DISCUSSION}

Presence of comorbid hypertension and type 2 diabetes is often associated with underlying metabolic disorders and central obesity. The combined sequelae lead to increased incidence of disease complications, and ultimately decreased patient life span. In this study, features of hormonal and metabolic disorders in patients with arterial hypertension and type 2 diabetes were investigated. The most significant signals identified were regulators of lipid and carbohydrate metabolisms, insulin resistance, and systemic inflammation development.

The data presented here indicated that all known manifestations of metabolic abnormalities dramatically increase with BMI in the cohort. The results suggested that in hypertensive patients with diabetes mellitus adipose tissue signaling was dysfunctional. Additionally, carbohydrate metabolism signaling alterations demonstrated that metabolic and hormonal signals were disrupted when hypertensive patients also had comorbid T2DM. The data suggested close pathogenetic links between onset of metabolic disorders and expressions of adipokines (omentin, adiponectin, and resistin). Pro-inflammatory IL-6 secretion was also altered, which was a negative regulator of comorbid arterial hypertension and T2DM.

Mounting evidence supports that adipokines are essential to etiology of cardiometabolic disorders. Despite these findings, research directions continue to focus on obesity as the essential therapeutic target for reducing the risk of metabolic syndrome, T2DM, and associated cardiovascular complications. Given the widespread incidence of comorbid hypertension in diabetic patients, identifying new markers responsible for increased blood pressure during insulin resistance is a paramount research concern.

\section{Authors' contributions}

O. Bilovol contributed solely to this paper.

\section{Financial support and sponsorship}

None.

\section{Conflicts of interest}

There are no conflicts of interest.

\section{Patient consent}

All involved patients gave their consent forms.

\section{Ethics approval}

The study protocol was approved by the Local Ethics Committee of the Kharkov National Medical University and was performed in accordance to the Declaration of Helsinki.

\section{REFERENCES}

1. Pereira M, Lunet N, Azevedo A, Barros H. Differences in prevalence, awareness, treatment and control of hypertension between developing and developed countries. J Hypertens 2009;27:963-75.

2. Kearney PM, Whelton M, Reynolds K, Whelton PK, He J. Worldwide prevalence of hypertension: a systematic review. J Hypertens 2004;22:11-9.

3. Sur G, Sur M, Kudor-Szabadi L, Sur L, Sporis D, Sur D. Arterial hypertension - prevalence of risk factors and morbide associations that increase cardiovascular risk. Maedica (Buchar) 2010;5:34-40.

4. Kronborg CN, Hallas J, Jacobsen IA. Prevalence, awareness, and control of arterial hypertension in Denmark. $J$ Am Soc Hypertens 2009;3:19-24

5. Harrison L. Hypertension ER Visits Surge 25\% in Five Years Medscape 2014. Available from: http://www.medscape.com/ viewcollection/33205. [Last accessed on 21-03-2017]

6. Gorbas I, Smyrnova I. Epidemiology of arterial hypertension in Ukraine: results of the 25-year observation: PP.28.124. J Hypertens 2010;28:e485-6.

7. World Health Organization. Global report on diabetes. Geneva, 2016 Available from: http:/www.who.int/diabetes/global-report/en/. [Last Accessed on 08-03-2017].

8. Ametov AS, Demidova TIu, Galieva OR. Angiotensin converting enzyme inhibitors in the prevention and treatment of vascular complications of diabetes. Kardiologiia 2005;45:109-12. (in Russian)

9. Steppan CM, Bailey ST, Bhat S, Brown EJ, Banerjee RR, Wright CM, Patel HR, Ahima RS, Lazar MA. The hormone resistin links obesity to diabetes. Nature 2001;409:307-12.

10. Mancia G, Fagard R, Narkiewicz K, Redon J, Zanchetti A, Böhm M, 
Christiaens T, Cifkova R, De Backer G, Dominiczak A, Galderisi M, Grobbee DE, Jaarsma T, Kirchhof P, Kjeldsen SE, Laurent S, Manolis AJ, Nilsson PM, Ruilope LM, Schmieder RE, Sirnes PA, Sleight P, Viigimaa M, Waeber B, Zannad F, Redon J, Dominiczak A, Narkiewicz K, Nilsson PM, Burnier M, Viigimaa M, Ambrosioni E, Caufield M, Coca A, Olsen MH, Schmieder RE, Tsioufis C, van de Borne P, Zamorano JL, Achenbach S, Baumgartner H, Bax JJ, Bueno H, Dean V, Deaton C, Erol C, Fagard R, Ferrari R, Hasdai D, Hoes AW, Kirchhof P, Knuuti J, Kolh P, Lancellotti P, Linhart A, Nihoyannopoulos P, Piepoli MF, Ponikowski P, Sirnes PA, Tamargo JL, Tendera M, Torbicki A, Wijns W, Windecker S, Clement DL, Coca A, Gillebert TC, Tendera M, Rosei EA, Ambrosioni E, Anker SD, Bauersachs J, Hitij JB, Caulfield M, De Buyzere M, De Geest S, Derumeaux GA, Erdine S, Farsang C, Funck-Brentano C, Gerc V, Germano G, Gielen S, Haller H, Hoes AW, Jordan J, Kahan T, Komajda M, Lovic D, Mahrholdt H, Olsen MH, Ostergren J, Parati G, Perk J, Polonia J, Popescu BA, Reiner Z, Rydén L, Sirenko Y, Stanton A, Struijker-Boudier H, Tsioufis C, van de Borne P, Vlachopoulos C, Volpe M, Wood DA. 2013 ESH/ESC guidelines for the management of arterial hypertension: the Task Force for the Management of Arterial Hypertension of the European Society of Hypertension (ESH) and of the European Society of Cardiology (ESC). Eur Heart J 2013;34:2159-219.

11. Rydén L, Grant PJ, Anker SD, Berne C, Cosentino F, Danchin N, Deaton C, Escaned J, Hammes HP, Huikuri H, Marre M, Marx N, Mellbin L, Ostergren J, Patrono C, Seferovic P, Uva MS, Taskinen MR, Tendera M, Tuomilehto J, Valensi P, Zamorano JL; ESC Committee for Practice Guidelines (CPG), Zamorano JL, Achenbach S, Baumgartner H, Bax JJ, Bueno H, Dean V, Deaton C, Erol C, Fagard R, Ferrari R, Hasdai D, Hoes AW, Kirchhof P, Knuuti J, Kolh P, Lancellotti P, Linhart A, Nihoyannopoulos P, Piepoli MF, Ponikowski P, Sirnes PA, Tamargo JL, Tendera M, Torbicki A, Wijns W, Windecker S; Document Reviewers, De Backer G, Sirnes PA, Ezquerra EA, Avogaro A, Badimon L, Baranova E, Baumgartner H, Betteridge J, Ceriello A, Fagard R, Funck-Brentano C, Gulba DC, Hasdai D, Hoes AW, Kjekshus JK, Knuuti J, Kolh P, Lev E,
Mueller C, Neyses L, Nilsson PM, Perk J, Ponikowski P, Reiner Z, Sattar N, Schächinger V, Scheen A, Schirmer H, Strömberg A, Sudzhaeva S, Tamargo JL, Viigimaa M, Vlachopoulos C, Xuereb RG. ESC Guidelines on diabetes, pre-diabetes, and cardiovascular diseases developed in collaboration with the EASD: the Task Force on diabetes, pre-diabetes, and cardiovascular diseases of the European Society of Cardiology (ESC) and developed in collaboration with the European Association for the Study of Diabetes (EASD). Eur Heart J 2013;34:3035-87

12. Piya MK, McTernan PG, Kumar S. Adipokine inflammation and insulin resistance: the role of glucose, lipids and endotoxin. $J$ Endocrinol 2013;216:T1-15.

13. Gutch M, Kumar S, Razi SM, Gupta KK, Gupta A. Assessment of insulin sensitivity/resistance. Indian J Endocrinol Metab 2015;19:160-4.

14. Trzeciak-Ryczek A, Tokarz-Deptula B, Deptula W. Adipocytokines affecting the immune system - selected data. Centr Eur J Immunol 2011;36:92-4

15. Ouchi N, Parker JL, Lugus JJ, Walsh K. Adipokines in inflammation and metabolic disease. Nat Rev Immunol 2011;11:85-97.

16. Abd-Elbaky AE, Abo-ElMatty DM, Mesbah NM, Ibrahim SM Omentin and apelin concentrations in relation to obesity, diabetes mellitus type two, and cardiovascular diseases in Egyptian population. Int J Diabetes Dev Ctries 2016;36:52-8.

17. Zhou JY, Chan L, Zhou SW. Omentin: linking metabolic syndrome and cardiovascular disease. Curr Vasc Pharmacol 2014;12:136-43.

18. Kwon H, Pessin JE. Adipokines mediate inflammation and insulin resistance. Front Endocrinol (Lausanne) 2013;4:71

19. Benomar Y, Gertler A, De Lacy P, Crépin D, Ould Hamouda H, Riffault L, Taouis M. Central resistin overexposure induces insulin resistance through Toll-like receptor 4. Diabetes 2013;62:102-14.

20. Ronti T, Lupattelli G, Mannarino E. The endocrine function of adipose tissue: an update. Clin Endocrinol (Oxf) 2006;64:355-65.

21. Galic S, Oakhill JS, Steinberg GR. Adipose tissue as an endocrine organ. Mol Cell Endocrinol 2010;316:129-39.

22. Coelho M, Oliveira T, Fernandes R. Biochemistry of adipose tissue: an endocrine organ. Arch Med Sci 2013;9:191-200. 